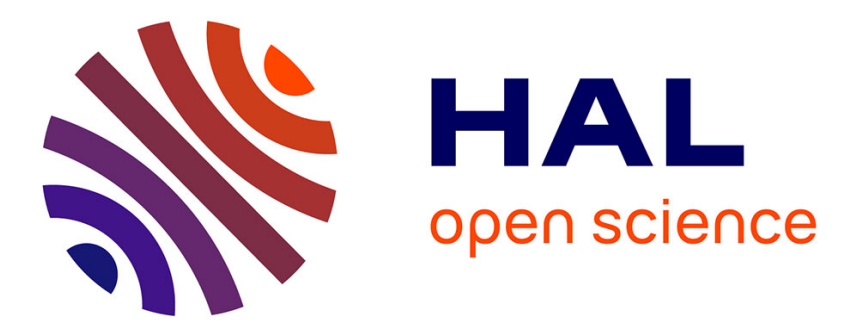

\title{
Optical Detection of Deuterium in Heavy Water: Towards Remote Detection of Tritium
}

M. Burger, P. J Skrodzki, L. Finney, J. Hermann, J. Nees, I. Jovanovic

\section{To cite this version:}

M. Burger, P. J Skrodzki, L. Finney, J. Hermann, J. Nees, et al.. Optical Detection of Deuterium in Heavy Water: Towards Remote Detection of Tritium. CLEO: Applications and Technology, 2019, San Jose, United States. pp.JTu2A.56, 10.1364/CLEO_AT.2019.JTu2A.56 . hal-02350876

\section{HAL Id: hal-02350876 https://hal.science/hal-02350876}

Submitted on 6 Nov 2019

HAL is a multi-disciplinary open access archive for the deposit and dissemination of scientific research documents, whether they are published or not. The documents may come from teaching and research institutions in France or abroad, or from public or private research centers.
L'archive ouverte pluridisciplinaire HAL, est destinée au dépôt et à la diffusion de documents scientifiques de niveau recherche, publiés ou non, émanant des établissements d'enseignement et de recherche français ou étrangers, des laboratoires publics ou privés. 


\title{
Optical Detection of Deuterium in Heavy Water: Towards Remote Detection of Tritium
}

\author{
M. Burger ${ }^{1,2 *}$, P. J. Skrodzki ${ }^{1,2}$, L. Finney ${ }^{1,2}$, J. Hermann ${ }^{3}$, J. Nees ${ }^{2}$ and I. Jovanovic ${ }^{1,2}$ \\ ${ }^{1}$ Department of Nuclear Engineering and Radiological Sciences, University of Michigan, Ann Arbor, MI 48109, USA \\ ${ }^{2}$ Center for Ultrafast Optical Science, University of Michigan, Ann Arbor, MI 48109, USA \\ ${ }^{3}$ Aix-Marseille University, CNRS, LP3, 13009, Marseille, France \\ *milosb@umich.edu
}

\begin{abstract}
Tritium detection poses a challenge because of the weak beta particle emission and absence of ionizing radiation. We demonstrate the isotopic analysis of deuterated water via laser-induced breakdown spectroscopy as a modality for measuring tritium.
\end{abstract}

OCIS codes: 020.3260 Isotope shifts 300.6365 Spectroscopy, laser induced breakdown 280.5395 Plasma diagnostics.

\section{Introduction}

Performing standoff detection of radionuclides is relevant in fields such as nuclear security and radiological safety [1]. Standoff delivery of a laser interrogation source is commonplace, and bright laser-induced plasmas are sources of abundant characteristic optical signal, making the laser-induced breakdown techniques well-suited for detection of various radionuclides, including tritium (T). Here we investigate such an approach based on the optical emission spectroscopy of laser-induced plasma [2], with an emphasis on detection of radioisotopes of interest in mixtures containing multiple isotopes of the same element. One of the challenges in employing LIBS to identify isotopic species is the degree of separation between closely spaced $(\sim \mathrm{pm})$ spectral lines. Prior related efforts include the quantitative detection of deuterium (D) and hydrogen $(\mathrm{H})$ retained in various fusion reactor components [3]. Due to the high cost and difficulty of obtaining T, we use $\mathrm{D}$ as a proxy. $\mathrm{H}$ and $\mathrm{D}$ are readily observable using optical emission spectroscopy at significant D concentrations under appropriate conditions. However, to detect lower D concentrations using this method, it is necessary to reduce the intense continuum emission and excessive Stark broadening, as well as enhance the characteristic line emission signal. Under reduced ambient pressure, species segregation in the plasma has also been shown to play a significant role, as the lighter species expand faster into surrounding gas.

The aim of this work is to investigate the effects of species segregation in laser-produced D-H plasma on the ability to resolve $\mathrm{D}_{\alpha}$ and $\mathrm{H}_{\alpha}$ isotope features and accurately reconstruct their relative concentrations.

(a)

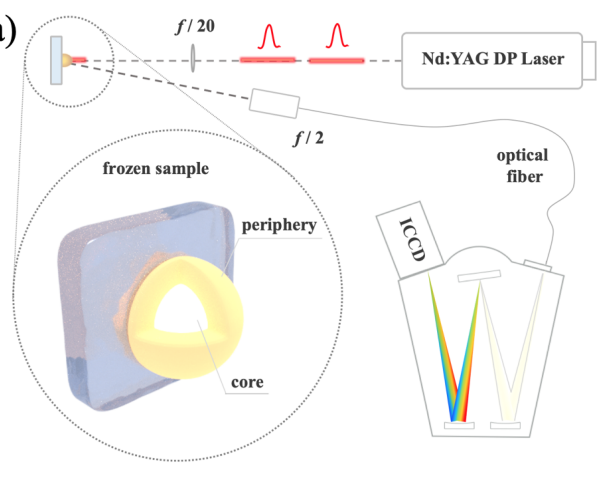



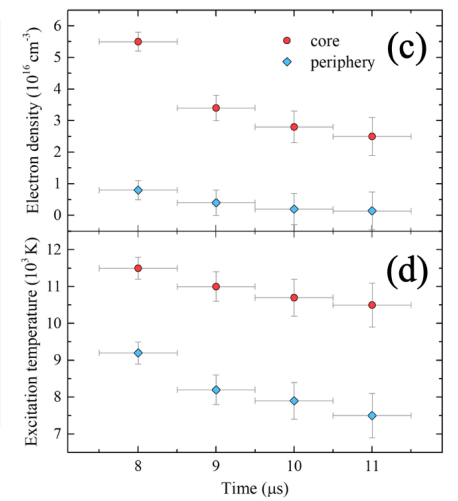

Fig. 1. (a) Setup for DP LIBS on a frozen $\mathrm{D}_{2} \mathrm{O}-\mathrm{H}_{2} \mathrm{O}$ mixture. The magnified section depicts the two-zone model [4]; (b) Measured and computed profiles of Balmer alpha spectral line at various delays after the laser pulse; Temporal evolution of (c) electron density and (d) excitation temperature of the plasma core and periphery. 

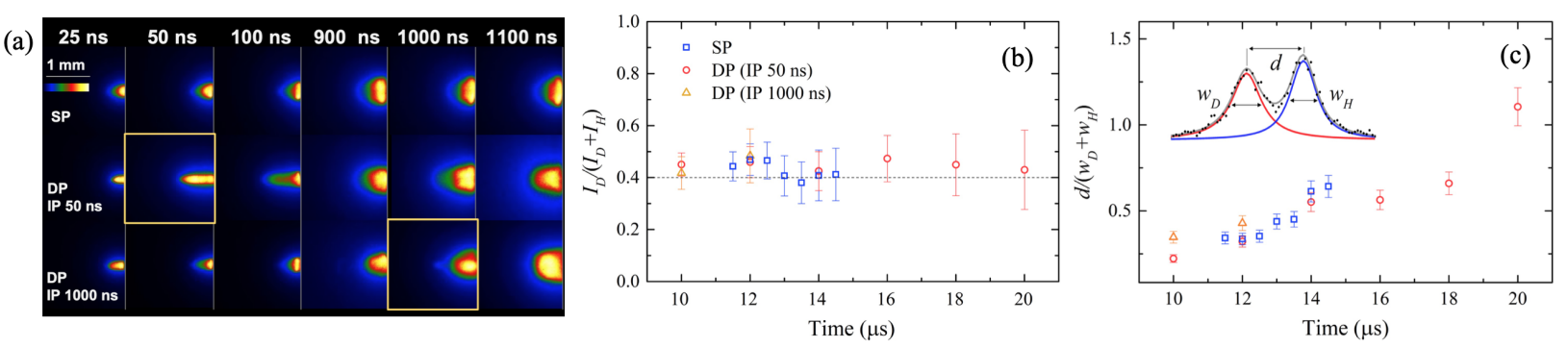

Fig. 2. (a) Plasma emission comparing SP and DP ablation with short (50-ns) and long (1000-ns) IP delays (yellow frame); Figures of merit for distinguishing $\mathrm{D}$ from $\mathrm{H}$ based upon the: (b) relative intensities, (c) line widths of the $\mathrm{D}_{\alpha}$ line $\left(w_{D}\right)$ and the $\mathrm{H}_{\alpha}$ line $\left(w_{H}\right)$ and their isotopic separation $d$. The dashed line indicates the intensity ratio expected for the isotopic ratio of the sample.

\section{Experiment, results and discussion}

The experiments (Fig. 1(a)) were performed with a compact, double pulse (DP) Nd:YAG laser, producing 10-ns, up to $140-\mathrm{mJ}$ pulses at the wavelength of $1064 \mathrm{~nm}$ and $10-\mathrm{Hz}$ repetition rate. The single pulse (SP) ablation experiments used $75-\mathrm{mJ}$ pulses, whereas DP experiments used $55 \mathrm{~mJ}$ and $75 \mathrm{~mJ}$ for the first and second pulse, respectively. Interpulse (IP) delay in the DP configuration was varied between short (50 ns) and long (1000 ns). The samples were prepared by mixing $40 \%$ deuterated water $\left(\mathrm{D}_{2} \mathrm{O}\right)$ with deionized water. The frozen mixture was mounted on a Peltier cooler. The plasma emission was collected with an $f / 2$ collimator, coupled into an optical fiber bundle and transferred to a Czerny-Turner spectrometer with a $0.55-\mathrm{m}$ focal length and a resolving power greater than $10^{4}$. The ICCD gate width was set to $1 \mu \mathrm{s}$. Spectroscopic data acquisition was performed in air by averaging over 200 ablation events. Plasma imaging (1:1) was performed by integrating over 30 ablation events using a 50-mm diameter, $75-\mathrm{mm}$ focal length achromatic lens and an ICCD detector operating with a gate width of $3 \mathrm{~ns}$. Figure 1(b) shows the SP experimental and computed profiles of superimposed $\mathrm{D}_{\alpha}$ and $\mathrm{H}_{\alpha}$ lines from the onset of spectral splitting $(8 \mu \mathrm{s})$ to the final stage of the Balmer beta lifetime $(11 \mu \mathrm{s})$. The electron density and excitation temperature trends were deduced from the simulated profiles, including contributions of plasma core and peripheral region (Fig. 1(c)).

Figure 2(a) compares the short and long IP delays for the DP scheme. The arrival of the second laser pulse in the short IP case causes elongation of the plume along the laser axis, whereas the second pulse in the long IP case causes a short-lived feature at the front edge of the plume, while having a negligible effect on the plume shape at later times. The negligible change of the plume shape seen in the long IP case indicates better laser-plasma coupling and a reduced rate of secondary ablation. Figure 2(b) shows one of the possible figures of merit (FOM) for distinguishing $\mathrm{D}$ from $\mathrm{H}$. We note the relatively constant trend for all ablation schemes, signifying the absence of notable segregation effects. Finally, we observe (Fig. 2(c)) the greatest distinction between $\mathrm{D}_{\alpha}$ and $\mathrm{H}_{\alpha}$ lines for long IP delay at earlier time steps. As a consequence, the agreement between experimental data and simulation implies that the isotopic fraction remains unchanged during the Balmer beta spectral line lifetime. We find that species segregation for laser-produced plasma formed in air does not significantly impact the ability to distinguish $\mathrm{D}_{\alpha}$ and $\mathrm{H}_{\alpha}$ Balmer lines for both the SP and DP laser ablation schemes. Significant reduction of broadening was observed in comparison to the SP configuration by employing the second, reheating pulse in a collinear geometry while using a lower-energy initial pulse. Thus, DP-LIBS offers a promising pathway towards remote detection of hazardous low-Z radionuclides (such as tritium) in air.

Funding \& Acknowledgements: National Science Foundation Graduate Research Fellowships Program (DGE 1256260); Department of Energy National Nuclear Security Administration, Consortium for Verification Technology (DE-NA0002534) and Nuclear Science and Security Consortium (DE-NA0003180 and DE-NA0000979).

\section{References}

1. T. Straume and A. Carsten, Health Phys. 65, 657 (1993).

2. B. Kearton and Y. Mattley, Nat. Photonics 2, 537 (2008).

3. L. Mercadier, C. Grisolia, H. Roche, A. Semerok, J. Hermann, et al, Fusion Sci. Technol. 60, 1049 (2011).

4. J. Hermann, D. Grojo, E. Axente, C. Gerhard, M. Burger, and V. Craciun, Phys. Rev. E 96053210 (2017).

5. M. Burger, P. J. Skrodzki, L. A. Finney, J. Hermann, J. Nees, and I. Jovanovic, Phys. Plasmas 25, 8 (2018). 